\title{
Bridging the Pressure Gap in CO Oxidation
}

\author{
Sara Blomberg,* Uta Hejral, Mikhail Shipilin, Stefano Albertin, Hanna Karlsson, Christian Hulteberg, \\ Patrick Lömker, Christopher Goodwin, David Degerman, Johan Gustafson, Christoph Schlueter, \\ Anders Nilsson, Edvin Lundgren, and Peter Amann
}

Cite This: ACS Catal. 2021, 11, 9128-9135

Read Online

ACCESS | Lلll Metrics \& More | 国 Article Recommendations | st Supporting Information

ABSTRACT: Performing fundamental operando catalysis studies under realistic conditions is a key to further develop and increase the efficiency of industrial catalysts. Operando X-ray photoelectron spectroscopy (XPS) experiments have been limited to pressures, and the relevance for industrial applications has been questioned. Herein, we report on the $\mathrm{CO}$ oxidation experiment on $\operatorname{Pd}(100)$ performed at a total pressure of 1 bar using XPS. We investigate the light-off regime and the surface chemical composition at the atomistic level in the highly active phase. Furthermore, the observed gas-phase photoemission peaks of $\mathrm{CO}_{2}, \mathrm{CO}$, and $\mathrm{O}_{2}$ indicate that the kinetics of the reaction during the light-off regime can be followed operando, and by studying the reaction rate of the reaction, the activation energy is calculated. The reaction was preceded by an in situ oxidation study in $7 \% \mathrm{O}_{2}$ in $\mathrm{He}$ and a total pressure of 70 mbar to confirm the surface sensitivity and assignment of the

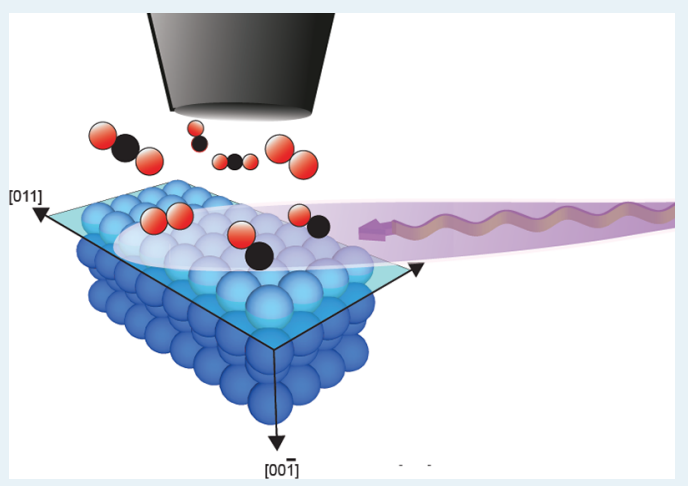
oxygen-induced photoemission peaks. However, oxygen-induced photoemission peaks were not observed during the reaction studies, but instead, a metallic Pd phase is present in the highly active regime under the conditions applied. The novel XPS setup utilizes hard X-rays to enable high-pressure studies, combined with a grazing incident angle to increase the surface sensitivity of the measurement. Our findings demonstrate the possibilities of achieving chemical information of the catalyst, operando, on an atomistic level, under industrially relevant conditions.

KEYWORDS: Pd(100), CO oxidation, XPS, high pressure, operando

\section{INTRODUCTION}

Palladium is a well-known catalyst for $\mathrm{CO}$ oxidation. The reaction has been studied for several decades, both for industrial applications and to gain a fundamental understanding of the reaction. To achieve fundamental knowledge of the reaction, model systems are often used and studied under well-controlled conditions at low pressures. ${ }^{1,2}$ This is in contrast to the industrial catalyst, which is operated in atmospheric pressure and above. The large difference under applied conditions, often referred to as the pressure gap, has generated an ongoing debate whether the results achieved at low pressures are relevant also for industrial conditions. ${ }^{3,4}$ It has also been recognized that if insights into the reaction mechanism are to be linked to surface structures, the catalyst characterization must be performed under reaction conditions, so-called operando studies. To fulfill the criteria of performing operando surface-sensitive experiments under realistic conditions, a significant effort has been made to develop experimental setups over the last decades. ${ }^{5-7} \mathrm{~A}$ well-known model system for fundamental studies of catalytic reactions is $\mathrm{CO}$ oxidation using $\mathrm{Pd}(100)$ as a catalyst. Several operando studies have been performed on the model system where knowledge of the surface structure on an atomistic level has been achieved. By using scanning tunneling microscopy, ${ }^{8}$ polarization modulated infrared reflection absorption spectroscopy, ${ }^{9}$ sum frequency generation, ${ }^{10}$ ambient pressure X-ray photoelectron spectroscopy (AP-XPS), ${ }^{11}$ and surface X-ray diffraction, ${ }^{12}$ the active phase of the $\operatorname{Pd}(100)$ surface has been investigated, and both metallic $\mathrm{Pd}$ and oxidized $\mathrm{Pd}$ have been concluded to be highly active. ${ }^{13-16}$ The active phase is not only dependent on the pressure applied but also on the ratio of $\mathrm{CO}$ and $\mathrm{O}_{2}$. A general trend is that $\mathrm{CO}$ poisoning occurs at low temperatures and high partial pressures of $\mathrm{CO}$ resulting in low activity in the reaction. By increasing the temperature, the $\mathrm{CO}$ molecules desorb, the light-off for the reaction is reached, and $\mathrm{Pd}(100)$ is highly active. For a broad partial pressure range of $\mathrm{CO}$ and $\mathrm{O}_{2}$, the surface oxide is reported to be observed after the light-off. ${ }^{16-18}$ The thicker PdO oxide formation has also been observed in the highly active phase when more

Received: February 19, 2021

Revised: June 11, 2021

Published: July 9, 2021 

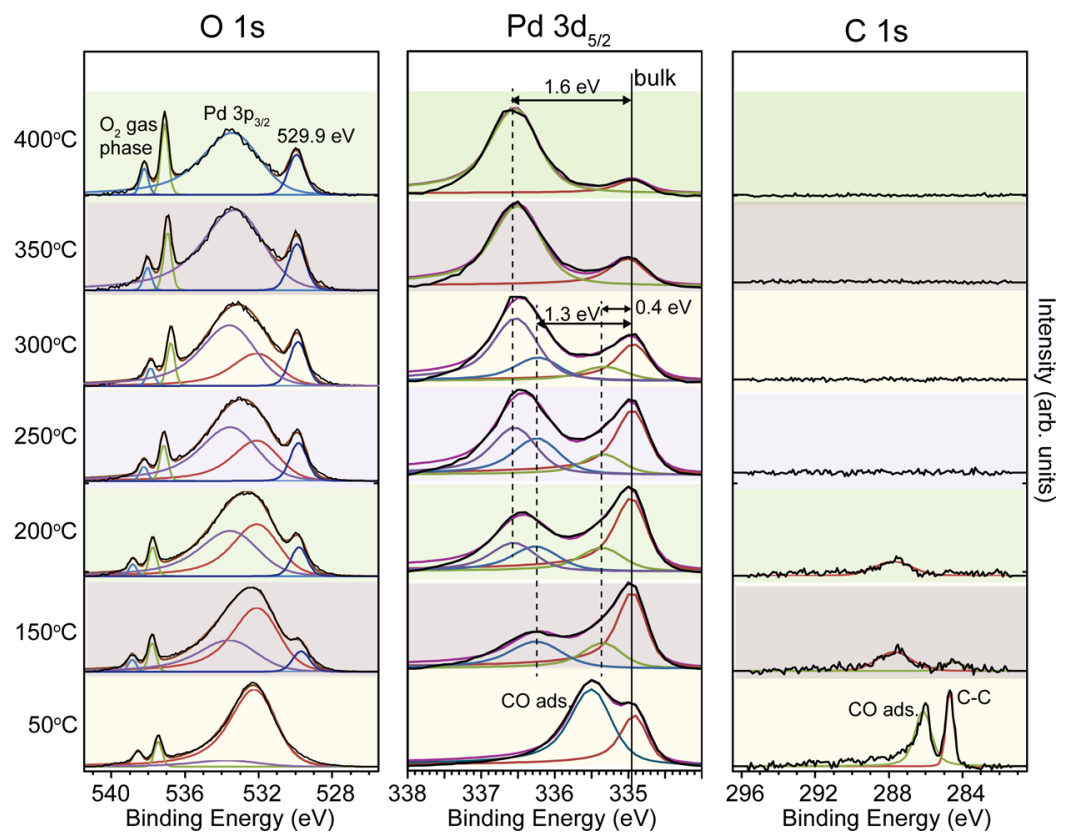

Figure 1. In situ oxidation of $\mathrm{Pd}(100)$ in the gas mixture of $7 \% \mathrm{O}_{2}$ in $\mathrm{He}$ at $70 \mathrm{mbar}$ total pressure. The temperature is increased in steps of $50{ }^{\circ} \mathrm{C}$ between $50{ }^{\circ} \mathrm{C}$ and $400{ }^{\circ} \mathrm{C}$. O $1 \mathrm{~s}, \mathrm{Pd} 3 \mathrm{~d}_{5 / 2}$, and $\mathrm{C} 1 \mathrm{~s}$ were measured at each temperature step to follow oxidation.

oxidizing conditions are applied. ${ }^{12,19}$ If the reaction conditions are switched from oxygen-rich to $\mathrm{CO}$ rich conditions, a metallic Pd surface is observed. ${ }^{?}$

When CO oxidation operando studies of model systems are performed, it has been reported that the geometry of the reactor and the gas flow have a significant impact on gas composition adjacent to the surface. ${ }^{20-23}$ In addition, in an oxygen rich environment, the reaction is most often mass transfer limited (MTL) by CO, immediately after light-off. ${ }^{9,24}$ This is observed as a plateau in the $\mathrm{CO}_{2}$ production, and the $\mathrm{CO}_{2}$ production is invariant to a further temperature increase. In this regime, the reaction rate is limited by the diffusion of $\mathrm{CO}$ molecules that reaches the catalyst. By monitoring the gas phase compositions by means of planar laser-induced fluorescence, the formation of a boundary layer of $\mathrm{CO}_{2}$ around the catalytically active surface has been visualized experimentally. ${ }^{25,26}$ The study also reveals that the formation of a boundary layer generates an oxidative environment close to the surface, highlighting the importance of measuring the gas phase close to the catalyst when operando studies are performed. To understand the interaction between the gas phase and active surface structure, simultaneous measurements using a combination of several techniques have recently been performed. In these studies, the gas phase, adjacent to the catalytic surface, is being probed simultaneously with the active catalyst surface. $^{21,27-29}$ Using AP-XPS, the gas phase and the surface chemical composition can be probed simultaneously, making AP-XPS a powerful technique for catalysis studies. The advantage of using electron-based techniques, such as XPS, is the surface sensitivity of the measurements enabling the observation of the interaction between the gas molecules and the active site. The short mean free path of the electrons, however, has limited the operando AP-XPS studies to tenths of millibar in working pressure. ${ }^{30,31}$ Technical developments utilizing membranes for pressure separation have made highpressure experiments possible, ${ }^{32-34}$ but the experiments have so far only been on static surfaces under pressure rather than observation of a catalyst during an ongoing reaction. Our previous AP-XPS study of CO oxidation on $\mathrm{Pd}(100)$ reports a pressure-dependent measurement using AP-XPS, up to a maximum operating pressure of $1 \mathrm{mbar}^{33}$ At a total pressure of $1 \mathrm{mbar}$ and $1: 1$ gas flow ratio of $\mathrm{CO} / \mathrm{O}_{2}$, a metallic Pd phase is observed immediately after light-off in the highly active phase of the reaction, which is in contradiction to what is observed at higher pressures using other probing techniques. ${ }^{8,15,36}$ To our knowledge, a full range pressure-dependent study of $\mathrm{CO}$ oxidation has not been performed previously using a surfacesensitive electron-based technique such as AP-XPS.

A new AP-XPS experimental setup (POLARIS) has been developed at Stockholm University that is currently placed at beamline P22 at the synchrotron PETRA III at Deutsches Elektronen-Synchrotron (DESY) in Hamburg, Germany. ${ }^{37,38}$ The novel setup allows for operando experiments performed at $1 \mathrm{bar}$ and above, and industrial-like conditions can be applied. Here, results from an operando study of $\mathrm{CO}$ oxidation over $\mathrm{Pd}(100)$ at total pressures up to 1 bar are presented. In the study, we demonstrate that, by using hard X-ray photoelectron spectroscopy (HAXPES) at the POLARIS setup, it is possible to determine the surface chemical composition at high pressures. Furthermore, the transition from an inactive $\mathrm{CO}$ poisoned surface to a highly active phase of $\operatorname{Pd}(100)$ is followed operando, and knowledge about the surface of $\mathrm{Pd}(100)$ during $\mathrm{CO}$ oxidation conducted at a high pressure is achieved. The detection of gas-phase peaks in the spectra, originating from $\mathrm{CO}$ and $\mathrm{CO}_{2}$, is a clear indication of the activity of the $\operatorname{Pd}(100)$ surface, making it ideal for detailed studies in the light-off regime. Our study shows that there is no pressure gap at the $\mathrm{CO}$ to $\mathrm{O}_{2}$ ratio applied, which implies that the results achieved at a low pressure are also relevant under realistic conditions.

\section{EXPERIMENTAL METHODS}

The XPS experiment was carried out with the POLARIS ${ }^{37}$ setup positioned at beamline P22 at PETRA III at (DESY) in Hamburg. ${ }^{38}$ The endstation POLARIS utilizes hard X-rays, enabling in situ XPS experiments at significantly higher 

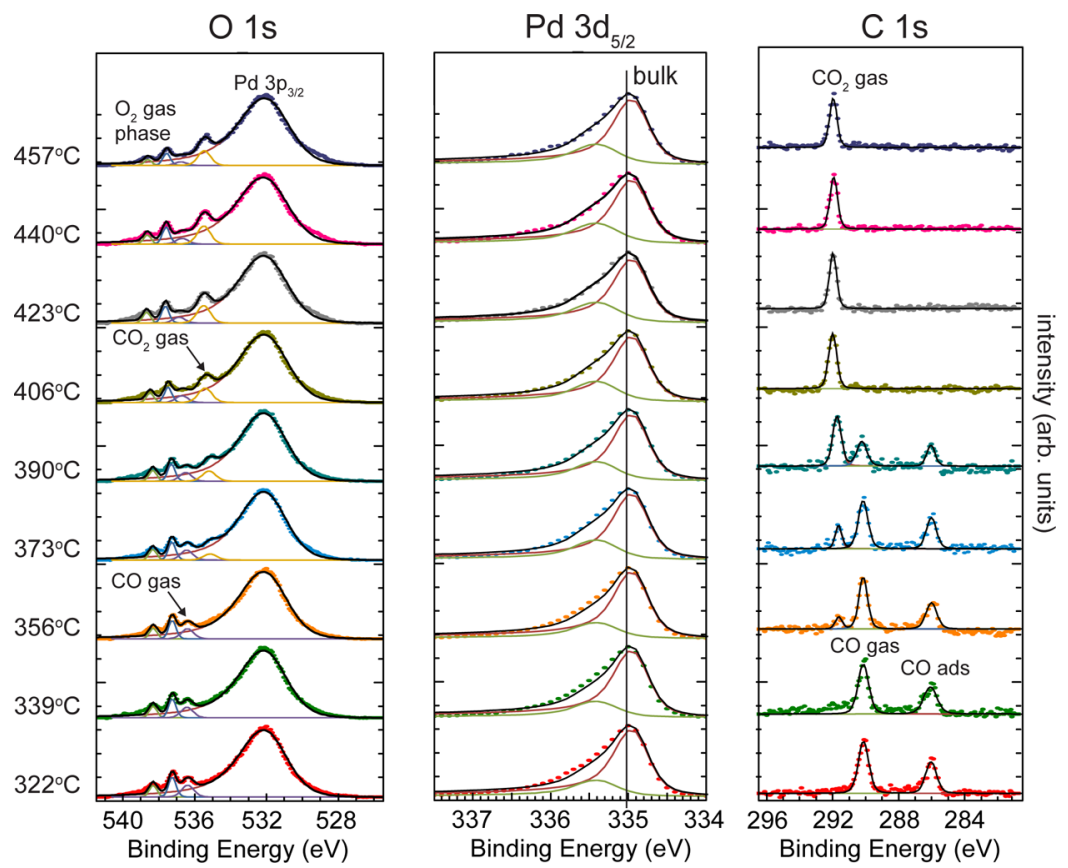

Figure 2. $\mathrm{Pd} 3 \mathrm{~d}_{5 / 2}, \mathrm{C} 1 \mathrm{~s}$, and $\mathrm{O} 1 \mathrm{~s}$ spectra were measured at a $1: 1$ gas flow ratio of $\mathrm{O}_{2}$ and $\mathrm{CO}$ at $100 \mathrm{mbar}$ total pressure. The temperature was continuously increased by $6^{\circ} \mathrm{C} / \mathrm{min}$, and the shown temperatures in the figure refer to the temperature when the $\mathrm{C} 1 \mathrm{~s}$ spectrum was recorded. At around $355^{\circ} \mathrm{C}, \mathrm{CO}_{2}$ is detected in the gas-phase in $\mathrm{C} 1 \mathrm{~s}$, which indicates that $\mathrm{Pd}(100)$ is active.

pressures than regular AP-XPS setups. Hard X-rays are used to generate a long inelastic mean free path of the photoelectrons, making regular HAXPES experiments bulk sensitive. At POLARIS, however, the incoming $\mathrm{X}$-rays are impinging on the sample surface at a grazing incident angle, close but below the critical angle of total external reflection, and the measurements can be performed with high surface sensitivity. The $\operatorname{Pd}(100)$ single crystal was probed with the incoming photon beam at an incidence angle of $0.6^{\circ}$ and a photon energy of $4600 \mathrm{eV}$, an energy for which the critical angle of $\mathrm{Pd}$ corresponds to around $0.8^{\circ} .{ }^{39}$ We estimate the probing depth to approximately $10 \AA$ for the Pd metal. To verify a surface sensitivity of the measurements using a grazing incidence angle, we follow the oxide growth in situ on the crystal. The surface oxide on $\operatorname{Pd}(100)$ has a $(\sqrt{ } 5 \times \sqrt{5}) \mathrm{R} 27^{\circ}$ structure and a thickness of one atomic layer, which corresponds to 2.374 $\AA^{36,40,41}$ In previous XPS and AP-XPS studies, we have characterized the $(\sqrt{5} \times \sqrt{5}) \mathrm{R}_{2} 7^{\circ}$ surface oxide in detail, which can be identified in the $\mathrm{Pd} 3 \mathrm{~d}_{5 / 2}$ and $\mathrm{O} 1 \mathrm{~s}$ spectra. It should be noted that the cross section for the s- and p-orbitals do not scale linearly with photon energy, which can be noted in the intensity ratio between the $\mathrm{O} 1 \mathrm{~s}$ and $\mathrm{Pd} 3 \mathrm{p}_{3 / 2}$ core levels when comparing soft and hard X-ray photoemission spectra. In addition, hard X-rays give rise to a slight shift in binding energy due to the recoil effect. ${ }^{42}$

\section{RESULTS AND DISCUSSION}

In situ Oxidation at a High Pressure. At the endstation, POLARIS, the surface sensitivity is enhanced by decreasing the incident angle of the X-rays close to the critical angle of the material. To confirm the surface sensitivity of the measurements and to achieve detailed insights into the oxidation process at high pressure, an in situ oxidation study of the $\mathrm{Pd}(100)$ surface was performed. Based on our previous studies, an oxidative environment is expected at the highly active phase of the $\mathrm{CO}$ oxidation reaction and a surface reconstruction may occur due to oxidation. The $\operatorname{Pd}(100)$ surface does not reconstruct due to interaction with $\mathrm{CO}$ neither thermalinduced reconstruction has been observed. ${ }^{43,44} \mathrm{~A}$ gas flow of $0.2 \mathrm{~L} / \mathrm{min} \mathrm{O}_{2}$ and $2.84 \mathrm{~L} / \mathrm{min} \mathrm{He}$, at a total pressure of 70 mbar, was applied in the oxidation experiment. The $\mathrm{Pd} 3 \mathrm{~d}_{5 / 2}$, $\mathrm{O} 1 \mathrm{~s}$, and $\mathrm{C} 1 \mathrm{~s}$ spectra were measured, while increasing the temperature from $50{ }^{\circ} \mathrm{C}$ to $400{ }^{\circ} \mathrm{C}$ (Figure 1 ). At $50{ }^{\circ} \mathrm{C}$, a bulk component at $335 \mathrm{eV}$ together with a peak shifted by $0.6 \mathrm{eV}$ is observed in the $\mathrm{Pd} 3 \mathrm{~d}_{5 / 2}$ spectrum. The observed core level shift in Pd 3d, together with the peak at $286 \mathrm{eV}$ in $\mathrm{C} 1$ s, agrees with previously reported values of adsorbed $\mathrm{CO}$ in the bridge site on metallic $\mathrm{Pd}(100) .{ }^{45,46}$ In $\mathrm{O} 1 \mathrm{~s}$, we observe the two oxygen gas phase peaks centered around $538 \mathrm{eV}$ together with $\operatorname{Pd} 3 \mathrm{p}_{3 / 2}$. An intensity increase of the gas phase peaks is observed with an increasing temperature, which is due to the thermal expansion of $\mathrm{Pd}(100)$ resulting in a smaller distance between the sample and the nozzle. ${ }^{47}$ By increasing the temperature to $150{ }^{\circ} \mathrm{C}$, a significant change in the $\mathrm{Pd} 3 \mathrm{~d}_{5 / 2}$ spectrum is observed. The metal bulk is still the most intense component, but two new components shifted by $0.4 \mathrm{eV}$ and $1.3 \mathrm{eV}$ are observed in the spectrum, which is consistent with the expected peak positions of two- and fourfold coordinated $\mathrm{Pd}$ atoms originating in the $(\sqrt{5} \times \sqrt{5}) \mathrm{R} 27^{\circ}$ surface oxide. ${ }^{41}$ The assignment of a surface oxide formation is also supported by the new peak observed at $529.9 \mathrm{eV}$ in the $\mathrm{O} 1 \mathrm{~s}$ spectrum. The peak at $529.9 \mathrm{eV}$ should contain two components originating from the two different oxygen species in the $(\sqrt{5} \times$ $\sqrt{5}) \mathrm{R} 27^{\circ}$ oxide, ${ }^{41}$ but the peaks cannot be resolved and are therefore fitted with a single component in the $\mathrm{O} 1 \mathrm{~s}$ spectra. This is also true for the Pd $3 p$ peak, where the two oxidation states of $\mathrm{Pd}$ cannot be resolved as clear as in the $\mathrm{Pd} 3 \mathrm{~d}$ core level. Therefore, $\mathrm{Pd} 3 \mathrm{p}$ is deconvoluted into two components corresponding to the metallic and oxidized $\mathrm{Pd}$, respectively. The oxidation of the surface implies that the majority of the $\mathrm{CO}$ desorb, which is also confirmed by the absent peak in the C 1s spectrum. By increasing the temperature further to 200 
${ }^{\circ} \mathrm{C}$, the oxide-related peak at $529.9 \mathrm{eV}$ in $\mathrm{O} 1 \mathrm{~s}$ is growing, and a new component with a surface core-level shift of $1.6 \mathrm{eV}$ is observed in the $\mathrm{Pd} 3 \mathrm{~d}_{5 / 2}$ spectrum. ${ }^{45}$ This is interpreted as a thicker oxide that is growing on the surface, and we suggest, supported by our previous results, that the thicker oxide grows in islands on the $(\sqrt{ } 5 \times \sqrt{ } 5) \mathrm{R} 27^{\circ}$ oxide. $^{36}$ The conclusion is based on the simultaneous observation of the components assigned to the surface oxide and the thicker oxide in the $\mathrm{Pd}$ spectrum. At 250 and $300{ }^{\circ} \mathrm{C}$, the intensity of the metallic bulk component at $335 \mathrm{eV}$ has decreased significantly compared to the oxide-related components, and at $400{ }^{\circ} \mathrm{C}$, it is barely detectable. At $400{ }^{\circ} \mathrm{C}$, a thicker $\mathrm{PdO}$ oxide covers the surface, which is also confirmed in the $\mathrm{O} 1 \mathrm{~s}$ spectrum, where the ratio between the oxide-related component at $529.9 \mathrm{eV}$ and $\mathrm{Pd} 3 \mathrm{p}_{3 / 2}$ has decreased significantly. The fitting of $\mathrm{Pd} 3 \mathrm{p}$ is challenging, and we have therefore chosen to fit only the main components in $\mathrm{Pd} 3 \mathrm{p}$.

Our results demonstrate that the growth of the oxide can be followed in situ in the $\mathrm{Pd} 3 \mathrm{~d}_{5 / 2}$ and $\mathrm{O}$ 1s spectra at high pressure using grazing incidence HAXPES. The assignment of the components in the spectra is supported by previous in situ low-pressure oxidation experiments. ${ }^{41}$ A higher temperature than expected is needed to observe an oxide formation on the Pd surface, which can be explained by the high gas flow that is directed toward the surface, which has a cooling effect on the surface. The temperature is measured with a type $\mathrm{N}$ thermocouple at the outer rim of the sample at the front side.

Operando CO Oxidation at High Pressure. In the reaction experiment, the $\operatorname{Pd}(100)$ single crystal is used as a model catalyst to gain a more in-depth knowledge of the $\mathrm{CO}$ oxidation reaction. In the reported experiment (Figure 2), a total pressure of 100 mbar was applied where an efficient gas transport was achieved by a stagnation flow geometry of the setup using a gas flow of $3.24 \mathrm{~L} / \mathrm{min}$ with $6 \% \mathrm{CO}$ and $\mathrm{O}_{2}$ each in a gas mixture with $\mathrm{He}$. The $\mathrm{Pd} 3 \mathrm{~d}_{5 / 2}, \mathrm{O} 1 \mathrm{~s}$, and $\mathrm{C} 1 \mathrm{~s}$ spectra were measured consecutively under these conditions, and the temperature was increased continuously from 320 to $460{ }^{\circ} \mathrm{C}$ $\left(6{ }^{\circ} \mathrm{C} / \mathrm{min}\right)$, which covers the regime before and after light-off of the reaction. In this study, we ascribe the light-off of the reaction to the moment when the $\mathrm{CO}_{2}$ signal can be observed in the $\mathrm{C} 1 \mathrm{~s}$ spectrum. Below light-off, a CO poisoned surface is present, which is concluded from a photoemission peak at 286 $\mathrm{eV}$ in $\mathrm{C} 1 \mathrm{~s}$, and a related component is observed as a shoulder in the $\mathrm{Pd} 3 \mathrm{~d}_{5 / 2}$ spectrum. The adsorbed $\mathrm{CO}$ is also detected in the $\mathrm{O} 1 \mathrm{~s}$ spectrum but it overlaps with $\mathrm{Pd} 3 \mathrm{p}_{3 / 2}$. In $\mathrm{O} 1 \mathrm{~s}$, the $\mathrm{CO}$ and $\mathrm{O}_{2}$ gas-phase peaks are observed, confirming that a gas mixture of the reactants is present close to the surface. At 320 ${ }^{\circ} \mathrm{C}, \mathrm{Pd}(100)$ is inactive and no $\mathrm{CO}_{2}$ can be detected, but by increasing the temperature to $355^{\circ} \mathrm{C}$, a peak correlated to gasphase $\mathrm{CO}_{2}$ appears in the $\mathrm{C} 1 \mathrm{~s}$ and $\mathrm{O} 1 \mathrm{~s}$ spectra. By increasing the temperature further, the $\mathrm{CO}_{2}$ gas-phase peak gradually increases, and a corresponding decrease is detected in the $\mathrm{CO}$ gas-phase signal. Surprisingly, $\mathrm{CO}$ is present in the gas phase and adsorbed at the surface at temperatures up to $405^{\circ} \mathrm{C}$. The results indicate that the reaction is not in the MTL regime immediately after light-off, and the measurement can be performed in the kinetic regime of the reaction. At $405{ }^{\circ} \mathrm{C}$, no $\mathrm{CO}$ gas can be detected anymore, and at the same temperature, all $\mathrm{CO}$ has desorbed from the surface. Above $405^{\circ} \mathrm{C}$, the reaction reaches a plateau in the $\mathrm{CO}_{2}$ production, which is interpreted as the MTL regime. In our oxidation study, we demonstrate that an oxidized $\operatorname{Pd}(100)$ surface can be recognized by a photoemission peak at $529.9 \mathrm{eV}$ in $\mathrm{O} 1 \mathrm{~s}$, but in the $\mathrm{CO}$ oxidation experiment, no clear evidence of surface oxidation can be observed. A metallic bulk component dominates the $\mathrm{Pd} 3 \mathrm{~d}_{5 / 2}$ spectrum, but an additional component shifted toward higher binding energy is also observed. We speculate that the peak is oxygen- or carbon-induced, but the nature behind this peak is not yet understood. A similar component was also observed in our previous AP-XPS results. $^{35}$ At high temperatures, a faint component at 529.9 $\mathrm{eV}$ can be observed, which supports our interpretation of chemisorbed oxygen on the surface.

Characteristic for the POLARIS setup is the high pressure that can be applied. We demonstrate the capacity of the setup by studying the surface structure of $\operatorname{Pd}(100)$ within the lightoff regime for $\mathrm{CO}$ oxidation at a 1:1 gas flow ratio of $\mathrm{CO}$ and $\mathrm{O}_{2}$ and total pressures up to 1 bar (Figure 3). To ensure to

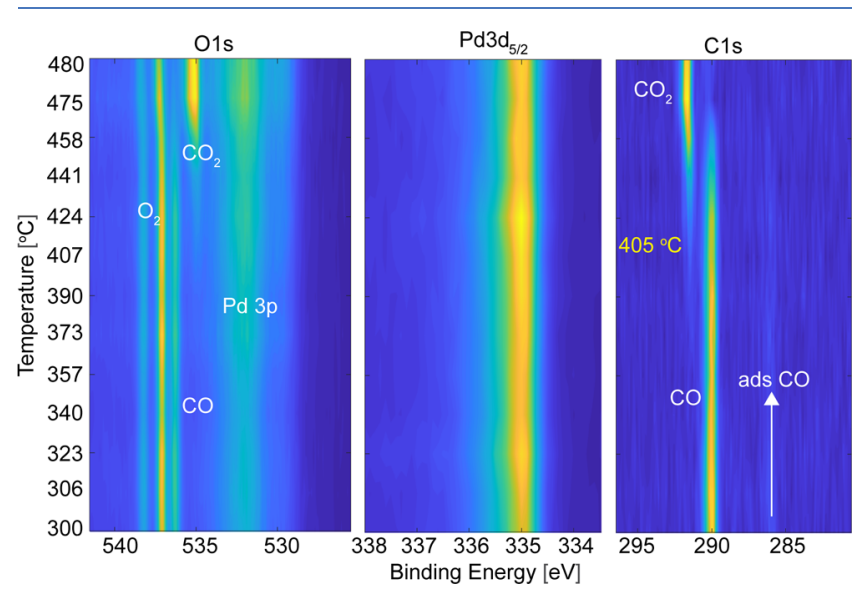

Figure 3. Light-off region for $\mathrm{CO}$ oxidation at a total pressure of 1 bar. The $\mathrm{O} 1 \mathrm{~s}, \mathrm{Pd} 3 \mathrm{~d}_{5 / 2}$, and $\mathrm{C} 1 \mathrm{~s}$ core levels are continuously measured, while the sample temperature is increased by $6{ }^{\circ} \mathrm{C} / \mathrm{min}$ of the $\mathrm{Pd}(100)$ crystal. The $\mathrm{CO}_{2}$ gas-phase peak presence is a clear marker of the light-off of the catalyst, which is around $405{ }^{\circ} \mathrm{C}$. The intensity of the spectra is color-coded, ranging from dark blue to yellow, where the latter indicates high intensity.

capture the entire light-off regime, we continuously increased the temperature of $\mathrm{Pd}(100)$ slowly by $6{ }^{\circ} \mathrm{C} / \mathrm{min}$, while measuring the $\mathrm{Pd} 3 \mathrm{~d}_{5 / 2}, \mathrm{O} 1 \mathrm{~s}$, and $\mathrm{C} 1 \mathrm{~s}$ core levels. The operating pressure of 1 bar is reached by decreasing the working distance between the nozzle and the sample surface to $20 \mu \mathrm{m}$. The gas composition of $6 \% \mathrm{O}_{2}$ and $\mathrm{CO}$ in He was used with a total gas flow of $5.18 \mathrm{~L} / \mathrm{min}$, which was $0.6 \mathrm{~L} / \mathrm{min}$ higher compared to the flow used for the measurements at lower pressures. The explored temperature window was between $300{ }^{\circ} \mathrm{C}$ to $480{ }^{\circ} \mathrm{C}$, and to keep the working distance, and thereby the pressure, constant over the entire temperature ramp, the sample was manually retracted when required to compensate for the thermal expansion of the crystal.

At 1 bar and 500 mbar (Figure S1 in Supporting Information), the light-off regime features a similar behavior as we observed at $100 \mathrm{mbar}$ total pressure. At $300{ }^{\circ} \mathrm{C}$, the $\mathrm{Pd}(100)$ surface is $\mathrm{CO}$ poisoned and the sample is inactive, which is confirmed by the absence of $\mathrm{CO}_{2}$ in the gas phase. By increasing the temperature of $\mathrm{Pd}(100)$, $\mathrm{CO}$ starts to desorb, and the light-off is observed at $375{ }^{\circ} \mathrm{C}$ at $500 \mathrm{mbar}$ total pressure and at $405{ }^{\circ} \mathrm{C}$ at 1 bar. When a maximum temperature of 450 and $480{ }^{\circ} \mathrm{C}$ for the study at $500 \mathrm{mbar}$ and $1 \mathrm{bar}$, respectively, is reached, almost full conversion of $\mathrm{CO}$ to $\mathrm{CO}_{2}$ is achieved and only a minor $\mathrm{CO}$ gas-phase peak is 
a) Light-off temp vs CO part pressure

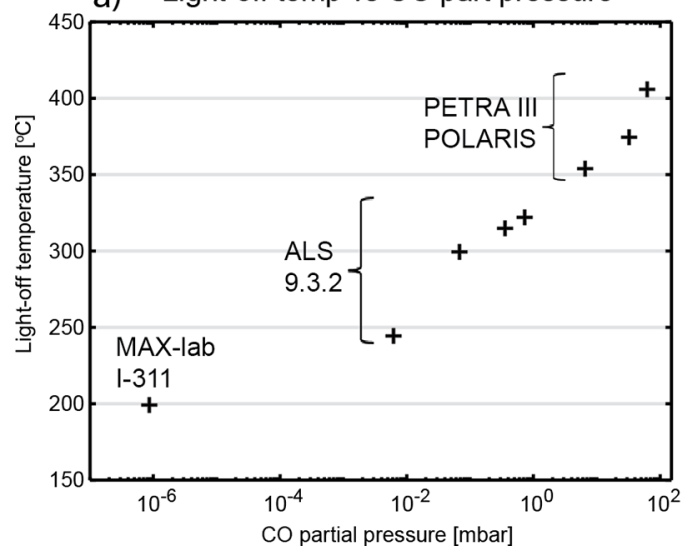

b)

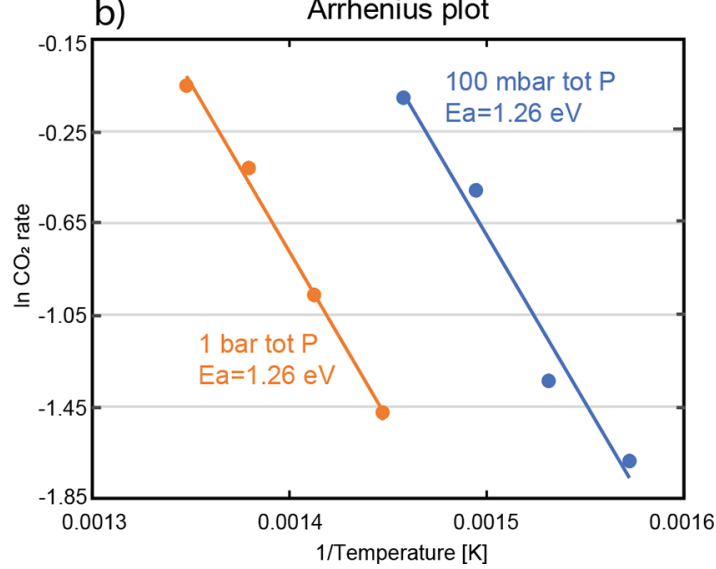

Figure 4. (a) Light-off temperature of the $\mathrm{Pd}(100)$ surface as a function of $\mathrm{CO}$ partial pressure. The measurements are performed at an increasing total pressure ranging from $10^{-6}$ mbar to $1 \mathrm{bar}$ in a 1:1 $\mathrm{CO}$ to $\mathrm{O}_{2}$ gas flow ratio. The synchrotron and beamline where the data are collected are indicated at each data point. (b) Apparent activation energy for $100 \mathrm{mbar}$ and $1 \mathrm{bar}$ is determined from the Arrhenius plot. The $\mathrm{CO}_{2}$ formation is extracted from the gas phase peak in the $\mathrm{C} 1 \mathrm{~s}$ spectra.

observed in C 1s. During the reaction, the Pd spectra do not change significantly and a metallic surface is observed (Figure S2 in Supporting Information). An oxide formation of the surface would give rise to a peak with a chemical shift of 1.3 or $1.6 \mathrm{eV},{ }^{45}$ but a peak at these binding energies was not detected at any of the applied conditions ranging from $10^{-6}$ mbar to 1 bar in total pressure.

Operando Study in the Kinetic Regime around the Light-Off. In this study, the light-off temperature of $\mathrm{Pd}(100)$ has been investigated at a 1:1 gas flow ratio of $\mathrm{CO}$ and $\mathrm{O}_{2}$ at pressures between 100 mbar to 1 bar total pressure. This gives additional insights into our previous results on the pressure dependence of the light-off temperature in the same ratio of $\mathrm{CO}$ and $\mathrm{O}_{2}$ using AP-XPS covering a pressure range from $10^{-6}$ mbar up to 1 mbar. The results are summarized in Figure $4 \mathrm{a}$, where the light-off temperatures of $\operatorname{Pd}(100)$ as a function of the partial pressure of $\mathrm{CO}$ are shown. The light-off of the reaction occurs within a temperature window of $200{ }^{\circ} \mathrm{C}$ for the whole pressure range, and an exponential dependence of the light-off temperature on pressure is found. The results presented in Figure $4 \mathrm{a}$ are generated from experiments conducted at three different endstations and synchrotrons (beamline I311 at MAX-laboratory, Sweden; beamline 9.3.2 at ALS, USA; beamline P22 at PETRA III, Germany), which may introduce uncertainties in the data points relative to each other due to differences in the experimental setup. However, the graph highlights the correlation between the light-off temperature and partial pressure of $\mathrm{CO}$ over a wide pressure range, spanning 9 orders of magnitude, establishing AP-XPS as a full pressure range technique.

The light-off regime is investigated in more detail. The simultaneous detection of adsorbed $\mathrm{CO}$ and $\mathrm{CO}_{2}$ in the gas phase over a wide temperature range at high pressure was surprising to us. A previous AP-XPS experiment with a standard gas flow configuration shows an abrupt change from a $\mathrm{CO}$ and $\mathrm{O}_{2}$ gas mixture to a $\mathrm{CO}_{2}$ and $\mathrm{O}_{2}$ mixture present above the surface, immediately after light-off. ${ }^{35}$ In contrast, the POLARIS setup has a high gas flow directed toward the surface, which we speculate suppresses the boundary layer of $\mathrm{CO}_{2}$ that is built up around the surface, ${ }^{20}$ and the surface is consequently facing less oxidizing conditions. After light-off, the $\mathrm{CO}_{2}$ signal is gradually increasing, while the photoemission peak, originating from the adsorbed $\mathrm{CO}$, decreases, indicating that the $\mathrm{CO}$ conversion scales with the number of Pd sites that become available when $\mathrm{CO}$ desorbs, which agrees of a reaction pathway according to the Langmuir-Hinshelwood mechanism. To investigate the kinetics during light-off, the effect of the sample temperature on the $\mathrm{CO}_{2}$ formation rate was plotted in an Arrhenius form for two total pressures (Figure 4b). During the experiments, no mass spectrometry data were recorded, and the $\mathrm{CO}_{2}$ formation rate is extracted from the area of the gas phase peaks in the $\mathrm{C} 1 \mathrm{~s}$ spectra for each temperature (Figure S3 in Supporting Information). The slope of the Arrhenius plots gives an apparent activation energy of $1.26 \mathrm{eV}(122 \mathrm{~kJ} / \mathrm{mol} \mathrm{K})$ for both $100 \mathrm{mbar}$ and 1 bar total pressure experiments. Similar activation energy has also been reported in previous studies on $\operatorname{Pd}(100)$ and other low index Pd surfaces, ${ }^{13,48,49}$ performed at low pressure and a CO coverage below $0.5 \mathrm{ML}$ on $\operatorname{Pd}(100),{ }^{48,49}$ which can be compared to the saturation coverage of $0.75 \mathrm{ML} .{ }^{46}$ In the same study, a decreasing apparent activation energy with increasing $\mathrm{CO}$ coverage of the surface is found, which is explained by an increasing repulsion interaction among the adsorbed $\mathrm{CO}$ molecules at higher coverage. Our finding of the same apparent activation energy for both, $100 \mathrm{mbar}$ and 1 bar total pressure, indicates that the reaction mechanism has the same ratelimiting step at both low and high total pressures. We speculate that the high gas flow and high temperatures at the operando measurements at POLARIS have a non-neglectable impact on the $\mathrm{CO}$ coverage and activation energy.

\section{CONCLUSIONS}

$\mathrm{CO}$ oxidation in a 1:1 gas flow ratio of $\mathrm{CO}$ and $\mathrm{O}_{2}$ using $\mathrm{He}$ as a carrier gas has been studied using $\operatorname{Pd}(100)$ as a model catalyst in a total pressure from 100 mbar up to 1 bar. The light-off regime has been studied in detail where the temperature, as well as the surface structure, has been monitored operando using AP-XPS. An oxidation study in a mixture of $\mathrm{O}_{2}$ and $\mathrm{He}$, with the increasing temperature, was performed to identify the oxidation degree of the Pd surface during $\mathrm{CO}$ oxidation. Our results show that we can follow the $\mathrm{CO}$ oxidation reaction operando by measuring the $\mathrm{Pd} 3 \mathrm{~d}_{5 / 2}, \mathrm{C}$ $1 \mathrm{~s}$ and $\mathrm{O} 1 \mathrm{~s}$ spectra, while increasing the temperature of the catalyst. The observed $\mathrm{Pd} 3 \mathrm{~d}_{5 / 2}$ core level reveals that metallic 
$\mathrm{Pd}$ is present in the highly active phase of the reaction immediately after light-off at all the applied conditions from low to high pressure. However, in the $100 \mathrm{mbar}$ regime and above, we expected an oxidized surface after light-off due to MTL of CO, as have been reported in previous studies. We speculate that the high gas flow in stagnation flow geometry results in an efficient gas transport of the reactants and products from the surface, which suppresses the boundary layer of $\mathrm{CO}_{2}$, and a less oxidative environment is present close to the surface. ${ }^{20}$ The gas-phase peaks detected in the O1s and $\mathrm{C} 1 \mathrm{~s}$ spectra are used to identify the activity of the catalyst surface, and the apparent activation energy is determined to be $1.26 \mathrm{eV}$ at both $100 \mathrm{mbar}$ and 1 bar total pressure.

Overall, herein we report on the first operando $\mathrm{CO}$ oxidation experiments performed using XPS at 1 bar total pressure, which has previously been limited to several orders of magnitude lower pressures. The present results complement our previous operando studies using XPS to investigate the light-off regime of $\mathrm{Pd}(100)$, where a total pressure range of 9 orders of magnitude has been covered. The study demonstrates the wide pressure range that can be investigated, generating the possibility of performing studies to bridge the so-called pressure gap in several chemical reactions. The temporal resolution of the measurement is sufficient to follow the gradually increased activity, which enables operando XPS studies in the kinetic regime of the reaction.

The POLARIS setup has unique possibilities of using photoemission for catalysis research under industrial conditions. The high surface sensitivity of the chemical composition allows for future operando studies probing the active site with an atomistic resolution of the catalyst under industrial conditions.

\section{ASSOCIATED CONTENT}

\section{SI Supporting Information}

The Supporting Information is available free of charge at https://pubs.acs.org/doi/10.1021/acscatal.1c00806.

Cleaning procedure of the sample, $\mathrm{CO}$ oxidation at 500 mbar total pressure, $\mathrm{C}$ 1s spectra at the light-off regime for 100,500 , and 1000 mbar, $\mathrm{Pd} 3 \mathrm{~d}_{5 / 2}$ spectra measured before light-off, at light-off, and after light-off, and Arrhenius plot data (PDF)

\section{AUTHOR INFORMATION}

\section{Corresponding Author}

Sara Blomberg - Department of Chemical Engineering, Lund University, Lund 221 00, Sweden; 이이.org/0000-00026475-013X; Email: sara.blomberg@chemeng.lth.se

\section{Authors}

Uta Hejral - Department of Physics, Lund University, Lund 22100, Sweden

Mikhail Shipilin - Department of Physics, AlbaNova University Center, Stockholm University, Stockholm 10691, Sweden

Stefano Albertin - Department of Physics, Lund University, Lund 221 00, Sweden

Hanna Karlsson - Department of Chemical Engineering, Lund University, Lund 221 00, Sweden

Christian Hulteberg - Department of Chemical Engineering, Lund University, Lund 221 00, Sweden; 다이.org/00000002-3502-5529
Patrick Lömker - Photon Science, Deutsches ElektronenSynchrotron DESY, Hamburg 22607, Germany

Christopher Goodwin - Department of Physics, AlbaNova University Center, Stockholm University, Stockholm 10691, Sweden

David Degerman - Department of Physics, AlbaNova University Center, Stockholm University, Stockholm 10691, Sweden

Johan Gustafson - Department of Physics, Lund University,

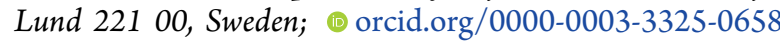

Christoph Schlueter - Photon Science, Deutsches ElektronenSynchrotron DESY, Hamburg 22607, Germany

Anders Nilsson - Department of Physics, AlbaNova University Center, Stockholm University, Stockholm 10691, Sweden; 이이.org/0000-0003-1968-8696

Edvin Lundgren - Department of Physics, Lund University, Lund 221 00, Sweden; 이이이.org/0000-0002-3692-6142

Peter Amann - Department of Physics, AlbaNova University Center, Stockholm University, Stockholm 10691, Sweden; Present Address: Peter Amann, Scienta Omicron AB, Danmarksgatan 22, 75323 Uppsala, Sweden

Complete contact information is available at: https://pubs.acs.org/10.1021/acscatal.1c00806

\section{Author Contributions}

All authors have given approval to the final version of the manuscript.

\section{Funding}

The work was supported by the Swedish Research Council (Vetenskapsrådet VR) within Röntgen-Ångström collaboration "Catalysis on the atomic scale" project number 349-20116491, the Global Climate and Energy Project (GCEP) at Stanford University, the Knut \& Alice Wallenberg (KAW) foundation project "Atomistic design of new catalysts" project number KAW2015.0058, and the Swedish Foundation for strategic research (Stiftelsen för Strategisk Forskning, SSF), proj. Nr. ITM 17-0034. The research leading to this result has been supported by the project CALIPSOplus under the Grant Agreement 730872 from the EU Framework Programme for Research and Innovation HORIZON 2020

\section{Notes}

The authors declare no competing financial interest.

\section{ACKNOWLEDGMENTS}

We acknowledge DESY (Hamburg, Germany), a member of the Helmholtz Association HGF, for the provision of experimental facilities. The research was carried out at the P22 beamline of Petra III.

\section{REFERENCES}

(1) Ertl, G. Reactions at Surfaces: From Atoms to Complexity (Nobel Lecture). Angew. Chem., Int. Ed. 2008, 47, 3524-3535.

(2) Somorjai, G. A.; Li, Y. Introduction to Surface Chemistry and Catalysis. 2nd ed.; Wiley: Hoboken, N.J., 2010; xii; p 771.

(3) Freund, H.-J.; Kuhlenbeck, H.; Libuda, J.; Rupprechter, G.; Bäumer, M.; Hamann, H. Bridging the Pressure and Materials Gaps between Catalysis and Surface Science: Clean and Modified Oxide Surfaces. Top. Catal. 2001, 15, 201-209.

(4) Rupprechter, G.; Weilach, C. Mind the Gap! Spectroscopy of Catalytically Active Phases. Nano Today 2007, 2, 20-29.

(5) Lundgren, E.; Zhang, C.; Merte, L. R.; Shipilin, M.; Blomberg, S.; Hejral, U.; Zhou, J.; Zetterberg, J.; Gustafson, J. Novel in Situ 
Techniques for Studies of Model Catalysts. Acc. Chem. Res. 2017, 50, 2326-2333.

(6) Frenken, J. W. M.; Groot, I. Operando Research in Heterogeneous Catalysis; Springer, 2017, pp 222.

(7) Toyoshima, R.; Kondoh, H. In-situobservations of catalytic surface reactions with soft $\mathrm{x}$-rays under working conditions. J. Phys.: Condens. Matter 2015, 27, 083003.

(8) Hendriksen, B. L. M.; Bobaru, S. C.; Frenken, J. W. M. Oscillatory Co Oxidation on $\mathrm{Pd}(100)$ Studied with in Situ Scanning Tunneling Microscopy. Surf. Sci. 2004, 552, 229-242.

(9) Gao, F.; Wang, Y.; Cai, Y.; Goodman, D. W. Co Oxidation on Pt-Group Metals from Ultrahigh Vacuum to near Atmospheric Pressures. 2. Palladium and Platinum. J. Phys. Chem. C 2009, 113, 174-181.

(10) Shen, Y. R. Surface properties probed by second-harmonic and sum-frequency generation. Nature 1989, 337, 519-525.

(11) Salmeron, M.; Schlogl, R. Ambient Pressure Photoelectron Spectroscopy: A New Tool for Surface Science and Nanotechnology. Surf. Sci. Rep. 2008, 63, 169-199.

(12) Gustafson, J.; Shipilin, M.; Zhang, C.; Stierle, A.; Hejral, U.; Ruett, U.; Gutowski, O.; Carlsson, P. A.; Skoglundh, M.; Lundgren, E. High-Energy Surface X-Ray Diffraction for Fast Surface Structure Determination. Science 2014, 343, 758-761.

(13) van Rijn, R.; Balmes, O.; Resta, A.; Wermeille, D.; Westerström, R.; Gustafson, J.; Felici, R.; Lundgren, E.; Frenken, J. W. M. Surface Structure and Reactivity of $\operatorname{Pd}(100)$ During Co Oxidation near Ambient Pressures. Phys. Chem. Chem. Phys. 2011, 13, 13167-13171.

(14) Mehar, V.; Kim, M.; Shipilin, M.; Van den Bossche, M.; Gustafson, J.; Merte, L. R.; Hejral, U.; Grönbeck, H.; Lundgren, E.; Asthagiri, A.; Weaver, J. F. Understanding the Intrinsic Surface Reactivity of Single-Layer and Multilayer Pdo(101) on Pd(100). ACS Catal. 2018, 8, 8553-8567.

(15) Gustafson, J.; Balmes, O.; Zhang, C.; Shipilin, M.; Schaefer, A.; Hagman, B.; Merte, L. R.; Martin, N. M.; Carlsson, P.-A.; Jankowski, M.; Crumlin, E. J.; Lundgren, E. The Role of Oxides in Catalytic Co Oxidation over Rhodium and Palladium. ACS Catal. 2018, 8, 44384445

(16) Toyoshima, R.; Yoshida, M.; Monya, Y.; Suzuki, K.; Mun, B. S.; Amemiya, K.; Mase, K.; Kondoh, H. Active Surface Oxygen for Catalytic Co Oxidation on $\mathrm{Pd}(100)$ Proceeding under near Ambient Pressure Conditions. J. Phys. Chem. Lett. 2012, 3, 3182-3187.

(17) Yu, Y.; Kim, D.; Lim, H.; Kim, G.; Koh, Y. E.; Kim, D.; Ueda, K.; Hiwasa, S.; Mase, K.; Bournel, F.; Gallet, J.-J.; Rochet, F.; Crumlin, E. J.; Ross, P. N.; Kondoh, H.; Noh, D. Y.; Mun, B. S. Operando Study of $\mathrm{Pd}(100)$ Surface During Co Oxidation Using Ambient Pressure X-Ray Photoemission Spectroscopy. AIP Adv. 2019, 9, 015314.

(18) van Spronsen, M. A.; Frenken, J. W. M.; Groot, I. M. N. Surface Science under Reaction Conditions: Co Oxidation on Pt and Pd Model Catalysts. Chem. Soc. Rev. 2017, 46, 4347-4374.

(19) Weaver, J. F.; Zhang, F.; Pan, L.; Li, T.; Asthagiri, A. VacancyMediated Processes in the Oxidation of Co on Pdo(101). Acc. Chem. Res. 2015, 48, 1515-1523.

(20) Zhou, J.; Matera, S.; Pfaff, S.; Blomberg, S.; Lundgren, E.; Zetterberg, J. Combining Planar Laser-Induced Fluorescence with Stagnation Point Flows for Small Single-Crystal Model Catalysts: Co Oxidation on a $\operatorname{Pd}(100)$. Catalysts 2019, 9, 484.

(21) Pfaff, S.; Zhou, J.; Hejral, U.; Gustafson, J.; Shipilin, M.; Albertin, S.; Blomberg, S.; Gutowski, O.; Dippel, A.; Lundgren, E.; Zetterberg, J. Combining High-Energy X-Ray Diffraction with Surface Optical Reflectance and Planar Laser Induced Fluorescence for Operando Catalyst Surface Characterization. Rev. Sci. Instrum. 2019, 90, 033703.

(22) Zhou, J.; Blomberg, S.; Gustafson, J.; Lundgren, E.; Zetterberg, J. Simultaneous Imaging of Gas Phase over and Surface Reflectance of a Pd(100) Single Crystal During Co Oxidation. J. Phys. Chem. C 2017, 121, 23511-23519.

(23) Blomberg, S.; Zetterberg, J.; Zhou, J.; Merte, L. R.; Gustafson, J.; Shipilin, M.; Trinchero, A.; Miccio, L. A.; Magaña, A.; Ilyn, M.;
Schiller, F.; Ortega, J. E.; Bertram, F.; Grönbeck, H.; Lundgren, E. Strain Dependent Light-Off Temperature in Catalysis Revealed by Planar Laser-Induced Fluorescence. ACS Catal. 2017, 7, 110-114.

(24) Matera, S.; Reuter, K. First-Principles Approach to Heat and Mass Transfer Effects in Model Catalyst Studies. Catal. Lett. 2009, 133, 156-159.

(25) Zetterberg, J.; Blomberg, S.; Gustafson, J.; Evertsson, J.; Zhou, J.; Adams, E. C.; Carlsson, P.-A.; Aldén, M.; Lundgren, E. Spatially and Temporally Resolved Gas Distributions around Heterogeneous Catalysts Using Infrared Planar Laser-Induced Fluorescence. Nat. Commun. 2015, 6, 7076.

(26) Blomberg, S.; Zhou, J.; Gustafson, J.; Zetterberg, J.; Lundgren, E. $2 \mathrm{~d}$ and $3 \mathrm{~d}$ Imaging of the Gas Phase Close to an Operating Model Catalyst by Planar Laser Induced Fluorescence. J. Phys.: Condens. Matter 2016, 28, 453002.

(27) Head, A. R.; Karslıoğlu, O.; Gerber, T.; Yu, Y.; Trotochaud, L.; Raso, J.; Kerger, P.; Bluhm, H. Co Adsorption on Pd(100) Studied by Multimodal Ambient Pressure X-Ray Photoelectron and Infrared Reflection Absorption Spectroscopies. Surf. Sci. 2017, 665, 51-55.

(28) Blomberg, S.; Zetterberg, J.; Gustafson, J.; Zhou, J.; Shipilin, M.; Pfaff, S.; Hejral, U.; Carlsson, P.-A.; Gutowski, O.; Bertram, F.; Lundgren, E. Combining Synchrotron Light with Laser Technology in Catalysis Research. J. Synchrotron Radiat. 2018, 25, 1389-1394.

(29) Onderwaater, W. G.; van der Tuijn, P. C.; Mom, R. V.; van Spronsen, M. A.; Roobol, S. B.; Saedi, A.; Drnec, J.; Isern, H.; Carla, F.; Dufrane, T.; Koehler, R.; Crama, B.; Groot, I. M. N.; Felici, R.; Frenken, J. W. M. Combined Scanning Probe Microscopy and X-Ray Scattering Instrument for in Situ Catalysis Investigations. Rev. Sci. Instrum. 2016, 87, 113705.

(30) Trotochaud, L.; Head, A. R.; Karslıoğlu, O.; Kyhl, L.; Bluhm, H. Ambient Pressure Photoelectron Spectroscopy: Practical Considerations and Experimental Frontiers. J. Phys.: Condens. Matter 2017, 29,053002 .

(31) Schnadt, J.; Knudsen, J.; Johansson, N. Present and New Frontiers in Materials Research by Ambient Pressure X-Ray Photoelectron Spectroscopy. J. Phys.: Condens. Matter 2020, 32, 413003.

(32) Takagi, Y.; Nakamura, T.; Yu, L.; Chaveanghong, S.; Sekizawa, O.; Sakata, T.; Uruga, T.; Tada, M.; Iwasawa, Y.; Yokoyama, T. X-Ray Photoelectron Spectroscopy under Real Ambient Pressure Conditions. Appl. Phys. Express 2017, 10, 076603.

(33) Weatherup, R. S.; Eren, B.; Hao, Y.; Bluhm, H.; Salmeron, M. B. Graphene Membranes for Atmospheric Pressure Photoelectron Spectroscopy. J. Phys. Chem. Lett. 2016, 7, 1622-1627.

(34) Velasco-Vélez, J. J.; Pfeifer, V.; Hävecker, M.; Wang, R.; Centeno, A.; Zurutuza, A.; Algara-Siller, G.; Stotz, E.; Skorupska, K.; Teschner, D.; Kube, P.; Braeuninger-Weimer, P.; Hofmann, S.; Schlögl, R.; Knop-Gericke, A. Atmospheric Pressure X-Ray Photoelectron Spectroscopy Apparatus: Bridging the Pressure Gap. Rev. Sci. Instrum. 2016, 87, 053121.

(35) Blomberg, S.; Hoffmann, M. J.; Gustafson, J.; Martin, N. M.; Fernandes, V. R.; Borg, A.; Liu, Z.; Chang, R.; Matera, S.; Reuter, K.; Lundgren, E. In SituX-Ray Photoelectron Spectroscopy of Model Catalysts: At the Edge of the Gap. Phys. Rev. Lett. 2013, 110, 117601.

(36) Shipilin, M.; Gustafson, J.; Zhang, C.; Merte, L. R.; Stierle, A.; Hejral, U.; Ruett, U.; Gutowski, O.; Skoglundh, M.; Carlsson, P.-A.; Lundgren, E. Transient Structures of Pdo During Co Oxidation over Pd(100). J. Phys. Chem. C 2015, 119, 15469-15476.

(37) Amann, P.; Degerman, D.; Lee, M.-T.; Alexander, J. D.; Shipilin, M.; Wang, H.-Y.; Cavalca, F.; Weston, M.; Gladh, J.; Blom, M.; Björkhage, M.; Löfgren, P.; Schlueter, C.; Loemker, P.; Ederer, K.; Drube, W.; Noei, H.; Zehetner, J.; Wentzel, H.; Åhlund, J.; Nilsson, A. A High-Pressure X-Ray Photoelectron Spectroscopy Instrument for Studies of Industrially Relevant Catalytic Reactions at Pressures of Several Bars. Rev. Sci. Instrum. 2019, 90, 103102.

(38) Schlueter, C.; Gloskovskii, A.; Ederer, K.; Schostak, I.; Piec, S.; Sarkar, I.; Matveyev, Y.; Lomker, P.; Sing, M.; Claessen, R.; Wiemann, C.; Schneider, C. M.; Medjanik, K.; Schonhense, G.; Amann, P.; 
Nilsson, A.; Drube, W. The New Dedicated Haxpes Beamline P22 at Petraiii. AIP Conf. Proc. 2019, 2054, 040010.

(39) Goodwin, C. M.; Shipilin, M.; Albertin, S.; Hejral, U.; Lömker, P.; Wang, H.-Y.; Blomberg, S.; Degerman, D.; Schlueter, C.; Nilsson, A.; Lundgren, E.; Amann, P. The Structure of the Active Pd State During Catalytic Carbon Monoxide Oxidization. J. Phys. Chem. Lett. 2021, 12, 4461-4465.

(40) Kostelník, P.; Seriani, N.; Kresse, G.; Mikkelsen, A.; Lundgren, E.; Blum, V.; Sikola, T.; Varga, P.; Schmid, M. The surface oxide: A LEED, DFT and STM study. Surf. Sci. 2007, 601, 1574-1581.

(41) Todorova, M.; Lundgren, E.; Blum, V.; Mikkelsen, A.; Gray, S.; Gustafson, J.; Borg, M.; Rogal, J.; Reuter, K.; Andersen, J. N.; Scheffler, M. The Pd()-R2 $7^{\circ}$-O surface oxide revisited. Surf. Sci. 2003, 541, 101-112.

(42) Takata, Y.; Kayanuma, Y.; Oshima, S.; Tanaka, S.; Yabashi, M.; Tamasaku, K.; Nishino, Y.; Matsunami, M.; Eguchi, R.; Chainani, A.; Oura, M.; Takeuchi, T.; Senba, Y.; Ohashi, H.; Shin, S.; Ishikawa, T. Recoil Effect of Photoelectrons in the Fermi Edge of Simple Metals. Phys. Rev. Lett. 2008, 101, 137601.

(43) Behm, R. J.; Christmann, K.; Ertl, G.; Van Hove, M. A. Adsorption of Co on $\operatorname{Pd}(100)$. J. Chem. Phys. 1980, 73, 2984-2995.

(44) Uvdal, P.; Karlsson, P.-A.; Nyberg, C.; Andersson, S.; Richardson, N. V. On the Structure of Dense Co Overlayers. Surf. Sci. 1988, 202, 167-182.

(45) Westerström, R.; Messing, M. E.; Blomberg, S.; Hellman, A.; Grönbeck, H.; Gustafson, J.; Martin, N. M.; Balmes, O.; van Rijn, R.; Andersen, J. N.; Deppert, K.; Bluhm, H.; Liu, Z.; Grass, M. E.; Hävecker, M.; Lundgren, E. Oxidation and Reduction of $\operatorname{Pd}(100)$ and Aerosol-Deposited Pd Nanoparticles. Phys. Rev. B: Condens. Matter Mater. Phys. 2011, 83, 115440.

(46) Andersen, J.; Qvarford, M.; Nyholm, R.; Sorensen, S.; Wigren, C. Surface Core-Level Shifts as a Probe of the Local Overlayer Structure - Co on Pd(100). Phys. Rev. Lett. 1991, 67, 2822-2825.

(47) Goodwin, C. M.; Alexander, J. D.; Weston, M.; Degerman, D.; Shipilin, M.; Loemker, P.; Amann, P. A Novel Method to Maintain the Sample Position and Pressure in Differentially Pumped Systems Below the Resolution Limit of Optical Microscopy Techniques. Appl. Spectrosc. 2021, 75, 137-144.

(48) Szanyi, J.; Goodman, D. W. Co Oxidation on Palladium .1. A Combined Kinetic-Infrared Reflection-Absorption Spectroscopic Study of Pd(100). J. Phys. Chem 1994, 98, 2972-2977.

(49) Gabasch, H.; Knop-Gericke, A.; Schlögl, R.; Borasio, M.; Weilach, C.; Rupprechter, G.; Penner, S.; Jenewein, B.; Hayek, K.; Klötzer, B. Comparison of the Reactivity of Different Pd-O Species in Co Oxidation. Phys. Chem. Chem. Phys. 2007, 9, 533-540. 